\title{
Proposal for a Robotic Platform Design for the Control and Monitoring of Physicochemical Parameters in Contaminated Water
}

\author{
Jennifer Catalina Murcia (Msc) ${ }^{1 *}$, MSc. Leydy J. Hernández Viveros (Msc) ${ }^{2}$, \\ Carlos Arturo Carrasco Henao (Msc) ${ }^{3}$ and Danilo A. López Sarmiento (PhD. $)^{4}$ \\ ${ }^{\text {I} C o r p o r a c i o ́ n ~ U n i v e r s i t a r i a ~ M i n u t o ~ d e ~ D i o s ~-~ U N I M I N U T O, ~ F a c u l t y ~ o f ~ E n g i n e e r i n g, ~ B o g o t a ́, ~ C o l o m b i a, ~ S o u t h ~ A m e r i c a . ~}$ \\ ORCID: 0000-0002-5724-6657 \\ ${ }^{2}$ Corporación Universitaria Minuto de Dios - UNIMINUTO, Faculty of Engineering, Bogotá, Colombia, South America. \\ ORCID:000-0002-1688-8775 \\ ${ }^{2}$ Corporación Universitaria Minuto de Dios - UNIMINUTO, Faculty of Engineering, Bogotá, Colombia, South America. \\ ORCID: 0000-0002-6148-3099 \\ ${ }^{3}$ Universidad Distrital Francisco José de Caldas, Faculty of Engineering, Bogotá, Colombia, South America. \\ ORCID: 0000-0002-8814-0600
}

\begin{abstract}
This article purpose is to describe the investigation carried out to design a robotic submersible platform for taking samples of contaminated water. This endeavor undertook a review of the actual robotic technologies used for aquatic exploration focusing the attention on low-cost designs. In recent years, the use of robotics is changing the approach to assess and control the impact that pollution is generating as a result of the human's industrial activities and modern life. Technology is helping to create a breakthrough in environmental management processes in a world more aware of the consequences of human activities and more concerned of making a change; for this reason, this research aims to outline a solution that could help the environmental regulatory agencies by providing a cost effective solution for monitoring levels of pollution in a safe manner, and ultimately could impact positively in the communities next to bodies of water, such as rivers or lakes, that are affected by a poor pollution.
\end{abstract}

Keywords: Robotic platform, programming language, engineering, competences, assisted design.

\section{INTRODUCTION}

Sampling and monitoring water bodies are a highly time and effort consuming tasks that involve taking a lot samples over a widespread areas, and try to make sense of the information of pollution, which is indeed statistically difficult to model, due to its intrinsic changing conditions. Robotic technologies for collecting pollution data is a field that is continuously growing and reaching new heights [1]. The possibilities that these technologies can provide are allowing to cover vast areas in oceans, rivers and other environments, and comprising a large amount of parameters that can be monitored, such as temperature, $\mathrm{pH}$, salinity, oxygen, oil traces, chemical plumes, toxins, and much more, with an unprecedented resolution and area coverage that can go from surface to deep water applications.

For the present investigation, the Fucha River was selected since is one of the most contaminated tributaries of Bogota River. This river runs for 12.5 kilometers from the El Delirio Forrest Reserve, located at the eastern hills of Bogota City, connecting various urban ecosystems and highly populated urban areas, until it reaches the Bogota River. The ecosystems found in this body of water include a variety of local and migrant bird species in an environment with a deep anthropogenic impact in terms of pollution and deterioration of physicochemical. Since 2010, different government and nongovernment organizations have been proposing a number of projects to intervene and decontaminate the Fucha River. Nevertheless, these efforts have not provided sufficient data to support the implementation of the proposed plans creating a lot of controversy about some of them, for instance the one to create a linear park alongshore of the river. The need for collecting reliable information to device effective plans for resolving the environmental problems of this river, motivated this project initiative for developing and designing such tool.

Monitoring pollution in this river is not easy due to the amount of contamination sources causing water conditions variations in time and location. A possible solution for sampling and monitoring may consist of implementing measurement stations along the river, but this approach requires a large number of sampling stations to each of the parameters and sites to be evaluated, making it quite difficult to execute, from the cost impact and infrastructure perspectives [2]. In order to take data in a more flexible and cost effective way, the use of mobile sensors with wireless communication capabilities seems to be 
a good approach for which robotics can provide the way to follow.

A multi-discipline team was gathered to undertake the challenge of developing and designing a submersible robotic platform as a tool to be used in monitoring water conditions for research and development of pollution control in Fucha River. The team combined knowledge in physics, mechanics, software engineering, electrical and electronic engineering to create the solution proposed in this article.

\section{RELATED STUDIES}

\subsection{Programming and platforms.}

Aquatic robots are categorized into two classes: underwater exploration and imitation of marine animal robots. The first one was chosen for the present work, given the contribution that these devices have, both theoretical and technical, which allowed to extract elements for the design, construction and commissioning of the developed platform.

The following summarizes some technologies associated with water use robots.

Researchers carried out a study by using an underwater video monitoring system for analyzing passive fishing techniques [3], which basically consist in laying a net to depth of 100 meters in a fixed position. The system allowed real-time visualization of the impact of this technique to all the marine life in the surroundings of the catch area.

In another research, an autonomous underwater explorer vehicle [4], was developed with maneuverable capabilities such as diving, emerging, evading obstacles, changing direction, exploring and detecting certain marks located at the bottom of a fish tank $150 \mathrm{~cm}$ long, $100 \mathrm{~cm}$ wide and $50 \mathrm{~cm}$ High. The underwater vehicle travelled along the surface in two modes: submerged and above the surface of the water. One of the main challenges of the project was to build a balanced robot, whose interior was totally isolated from the water.

A remotely operated vehicle ROV (Remotely Operated Vehicle) [5] was developed for underwater exploration, including real time communications capabilities. To control the movement of this ROV, the researchers developed the prototype using Simulink Matlab software tool to device the transfer function and PID controllers.

Researchers designed a mobile robot to execute monitoring tasks controlled via web [6], based on Orange PI $+2 \mathrm{E}$ and Arduino PC cards. The Robot is got a LCD touch screen provided for user interface. The robot was provided with four electrical motors, a charge controller, ultrasonic sensors and a camera. The system was programmed using is the ROS framework (Robot Operating System). The Orange PI card was programmed using Linux Server Operating system; the Orange PI card flexibility used multiple programming languages such as Java, PHP, Xajax and $\mathrm{SH}$, integrated to run as a single program interfacing through to a web browser for video capture from the camera, read the user commands and make the request to the Arduino card for sensing, processing and acting tasks.

Another case to mention is the design of a robot for aquatic cleaning [7]. The prototype included a floating mechanical structure, locomotion, an arm for collecting material floating on water, sensing and control elements. This robot was capable of collect and transport floating pieces on water, with the size and weight of a ping pong ball, to unload them on the shore of a pool or lake.

Although the robots resolved problems like underwater exploration, obstacle detection, capture of underwater images, among other applications, none of them measures the physicochemical (temperature, $\mathrm{pH}$, turbidity) and biological insitu parameters of water bodies. Therefore, developing the design of a robotic platform to carry out these measurements, is quite relevant. Among other benefits, the prevention of exposure of humans for taking samples is avoided.

Regarding the software used in robotics, the market offers a number of economic tools such as Moway (2014), Epuck (2014), or LEGO Mindstorms (2014). These tools are composed of controllers, electronic sensors, low-cost mechanical systems and / or small robots. Although they do not provide the same precision as industrial robots, they are sufficient for R\&D processes.

To remark from these robotics tools is their multidisciplinary nature; they feature the possibility to integrate a multidiscipline team whose members can be assigned specific tasks such as mechanical design and physical development of the robot, programming of the different subsystems [8], development of strategies, implementation of behaviors, validation of software, among other aspects.

The low-cost robotic platforms use embedded software cards and open-source hardware [9]. These cards, despite their low cost can have a performance similar to those of $\mathrm{PC}$, but with a substantial price difference. The most widely used tools are Arduino (2014), Raspberry (2014) and Beagle Board (2014); for the case of this work Arduino (2014) was selected, due to its computing and communication capabilities that allows the development of complex prototypes.

\section{MATERIALS AND METHODS}

\subsection{Research method.}

The quantitative approach of the descriptive type [10] was used during this investigation. This approach was used to develop the mechanical, electronic and programming specifications required for the design of the submersible platform and the sampling of physicochemical variables of water. 
To develop such specifications, the available literature about submersible platforms and methods of sampling of water used in the industrial sector was consulted. The study was carried out in the following phases; first, a theoretical review about principles and operations of didactic robotic platforms was conducted. The second phase used the knowledge gathered during the first phase, to move on to the design and simulation stage. The third phase, construction, applied quantitative data to make the programming of the variables, counting times, displacement and speed of the equipment, as well as the control of tasks and processes of the robot.

\subsection{Categories of analysis.}

Table 1 describes the categories of project development analysis.

Table 1. Categories of analysis.

\begin{tabular}{|l|l|}
\hline Category & Description \\
\hline $\begin{array}{l}\text { Programming } \\
\text { Software }\end{array}$ & $\begin{array}{l}\text { Analysis of technical specifications for the } \\
\text { selection of software required in the } \\
\text { programming of the physicochemical } \\
\text { variables of water. }\end{array}$ \\
\hline $\begin{array}{l}\text { Platform } \\
\text { Design }\end{array}$ & $\begin{array}{l}\text { Structural design of the platform and } \\
\text { selection of materials, based on the } \\
\text { specifications to meet the requirements for } \\
\text { movement, resistance, durability and ease } \\
\text { of immersion in water. }\end{array}$ \\
\hline Simulation & $\begin{array}{l}\text { Function test prior to physical } \\
\text { construction, to verify mechanical, } \\
\text { electronic factors and programming } \\
\text { algorithms. }\end{array}$ \\
\hline
\end{tabular}

From the previous categories [10], activities were carried out such as plan designs (CAD) as shown in Figure 1, programming algorithms, electronic design, which allowed the construction of the aquatic robotic platform, and testing. This robot can be used a teaching-learning resource in students of first semesters of engineering.

For the validation of the design, water samples were taken from the river, at different seasons of the year (dry season and rainy season) and in two different places: Cruz Verde wasteland river origin and at the end of the wasteland, in order to compare acidity and temperature levels, these were the variables to consider in the investigation and thus test the operation of the robotic submersible system, to check movements and sensors.

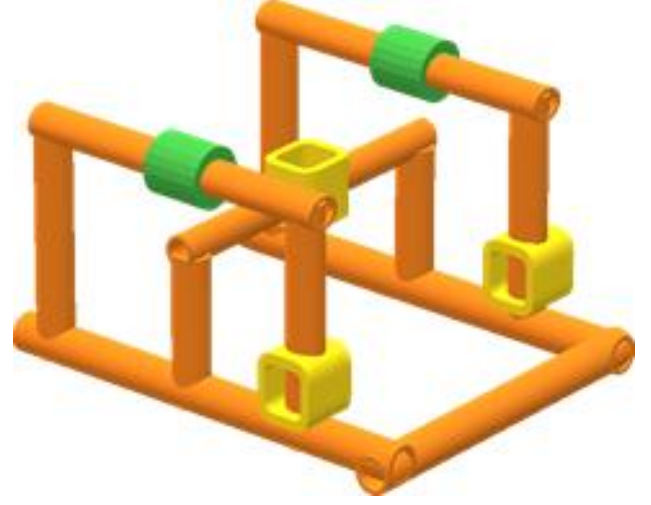

Figure 1. Platform sketch through TinkerCad. Own elaboration, 2019.

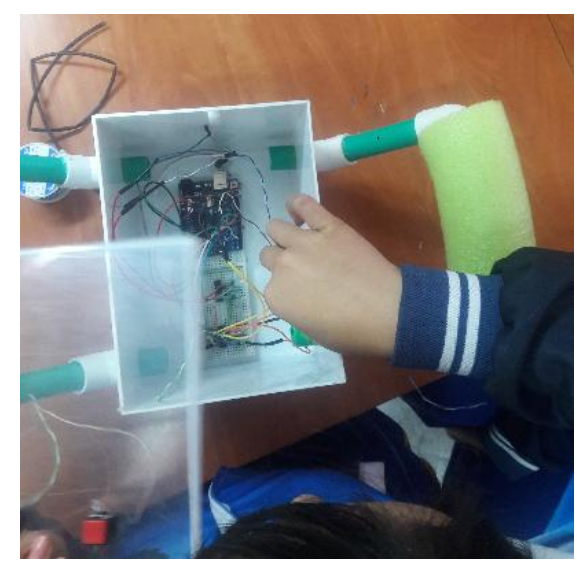

Figure 2. Implementation work sessions with students.

\section{RESULTS}

The main objective as mentioned initially, was to design a submersible robotic platform for collecting polluted water samples and monitoring of physicochemical parameters. To achieve this the following stages were followed:

Stage 1. Structure design: design sketches were made, considering spaces for sensor installation (temperature, humidity and $\mathrm{pH}$ ). A final design for 3D printing was obtained.

Stage 2. Programming language: Arduino IDE was used to develop the robot control software. To implement the locomotion of the submersible platform, 12 volt DC 100 RPM motors with reduction, temperature sensor and $\mathrm{pH}$ were required for Arduino card, among other components.

The final integration of the system was carried out by groups of students who participated in the development of mechanical prototypes, implementation of programming algorithms, implementation of electro-electronic components, tests (see Figure 2).

\section{DISCUSSION}

According to the literary review, ROVs are currently being used to carry out underwater research and exploration work, 
however, their cost is high due to their need for robustness; taking into account the scope, on the best didactic prototype solution for immersions in turbulent or contaminated waters, a submarine-type scheme reference is proposed by Sea Perch. The added value of this project is to promote the use of technologies in conventional processes, and these technologies can arise through academic research work, where a solution for work activities related to the contact of contaminated water is delivered and in turn strengthen the academy to from jobs such as the construction of platforms and robotic designs at the service of the community.
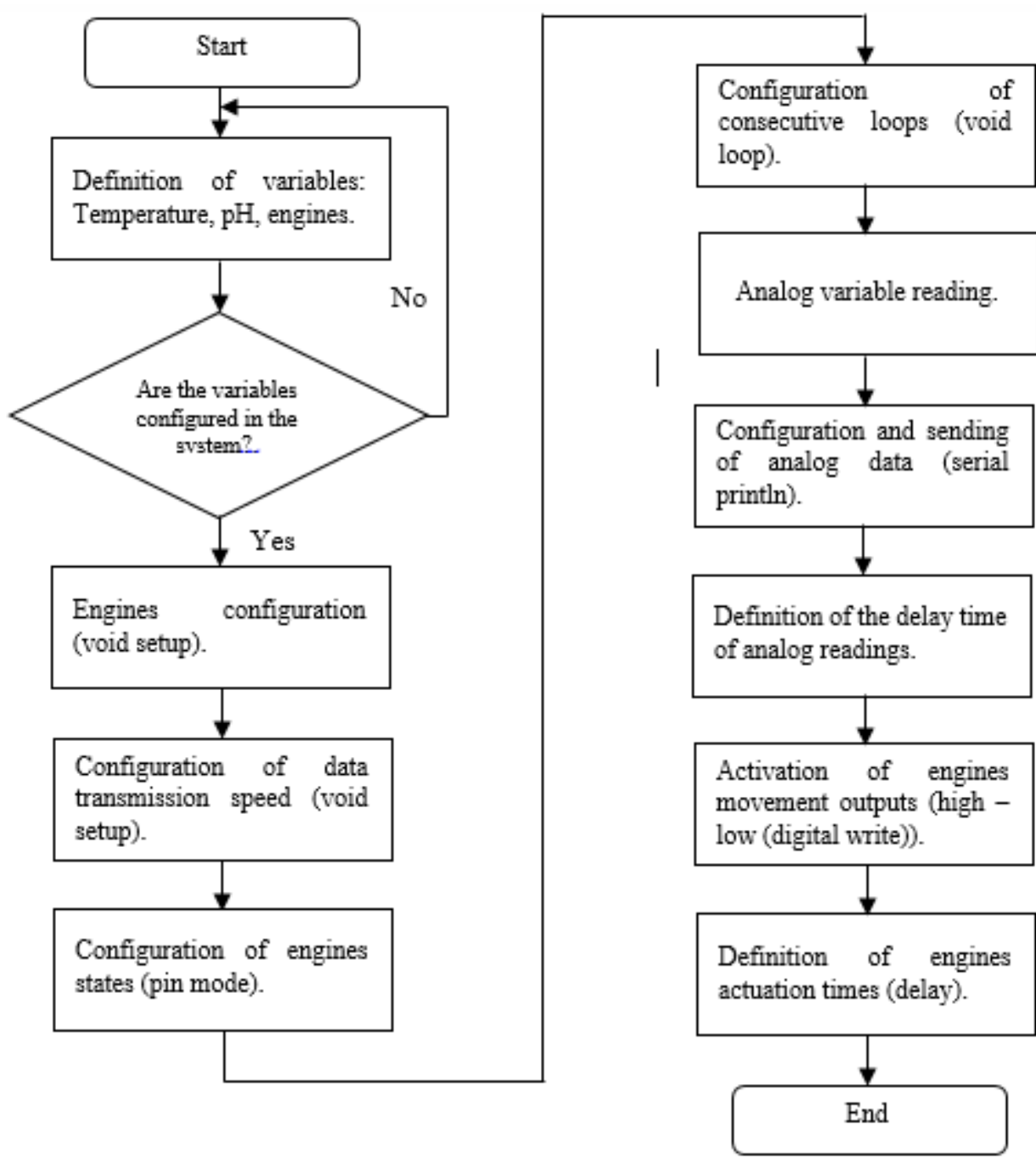

Figure 3. Flowchart monitoring the design.

\section{CONCLUSIONS}

Tests were performed at the geographical points referenced above, checking electric motors operation and sensors data collection, in the results it was found that the robotic device allows to submerge and take the temperature and $\mathrm{pH}$ values, for the follow-up of the design a flow chart (see Figure 3 ).

For their respective reading, it was necessary to identify the real data of temperature and of $\mathrm{pH}$, so that these are loaded into the programming language, in this way maximum and minimum ranges are established to make the reading of the water parameters, this will allow to determine level of acidity of the same and increase of temperature by contamination, which is finally what is required to analyze with the samples taken.

\section{ACKNOWLEDGMENTS}

Thanks to all those who have been involved in the development and execution of the research, In special to Corporación Universitaria Minuto de Dios, Universidad Francisco José de Caldas and the TdRobotic Company.References.

\section{REFERENCES}

[1] D. Rodríguez-Gómez; Usos problemáticos de las TIC entre jóvenes en su vida personal y escolar, Revista Científica de Educomunicación, Volume 26, Issue 56, pp. 91-100, 2018, doi: https://doi.org/10.3916/C562018-09. 
[2] J. González, M. Estebanell, M. Peracaula; ¿Robots o programación?, El concepto de pensamiento computacional y los futuros Maestros, Education in the Knowledge Society, Volume 19, Issue 2, pp. 2945, 2018, doi: http://dx.doi.org/10.14201/eks20181922945.

[3] United States Environmental Protection Agency; United States Environmental Protection Agency, Agosto 2019. [Online]. Available: https://www3.epa.gov/acidrain/education/site_studen ts_spanish/phscale.html.

[4] R. Hernández, C. Fernández, P. Baptista, Metodología de la investigación, México: Editorial: McGraw-Hill, ISBN: 968-422-931-3, 2014.

[5] Ministerio de Salud y Protección Social; Informe Nacional de la calidad del agua para consumo Humano, año 2013 con base en el IRCA, Ministerio de salud y protección Social, Bogotá, 2014.

[6] M. González; Reducción de contaminantes atmosféricos e hídricos en agricultura de precisión utilizando sistemas robotizados, Doctoral Thesis, Universidad de León: Escuela de Ingenierías Industrial e Informática Departamento de Ingeniería Eléctrica y de Sistemas y Automática, 2016.

[7] J. Martínez y S. Vaquen, Diseño de una plataforma robótica para el monitoreo de variables del ambiente acuático, Universidad Libre de Bogotá, Bogotá: VII Congreso Internacional de Ingeniería Mecánica, Bogotá, Colombia, 2015.

[8] J. Leiva, J. Valero; Diseño y desarrollo de un prototipo robótico con Orange PI, Investigación e Innovación en ingenierías, Volume 5, Issue 2 pp. 174-189, 2017, doi: https://doi.org/10.17081/invinno.5.2.2760.

[9] F. Hidalgo; Diseño de un sistema de monitoreo submarino por video para el estudio científico de artes de pesca pasivos de poca profundidad en el Perú, Pontificia Universidad Católica del Perú, Facultad de Ciencias e Ingeniería, Perú, 2009.

[9] Ministerio de Ambiente y Desarrollo Sostenible, Diagnóstico Nacional de salud Ambiental, Bogotá, 2012.

[10] R. Hernández, C. Fernández y P. Baptista, Metodología de la investigación, México: McGrawHill, 2014. 